\title{
Elegia ao Professor Eduardo Torres
}

Sras e Srs, bom dia!

É com muita honra que saúdo em nome do Departamento de Fisiologia e Farmacologia (DFF) a família do nosso saudoso colega, Prof. Eduardo Augusto Torres da Silva, por ocasião de sua denominação para o novo Biotério Setorial do Campus do Porangabussu da Universidade Federal do Ceará.

Trata-se de justa homenagem da Instituição a que se dedicou a vida inteira. Egresso do curso de Engenharia da UFC, partiu em 1973 para o Rio de Janeiro onde obteve Mestrado pelo Instituto de Biofísica (hoje Carlos Chagas) da Universidade Federal do Rio de Janeiro, com a dissertação "Modelo tetracompartimental da cinética do Iodo: solução matemática e proposição de modelo eletroanalógico" sob a orientação da Profa. Doris Rosenthal.

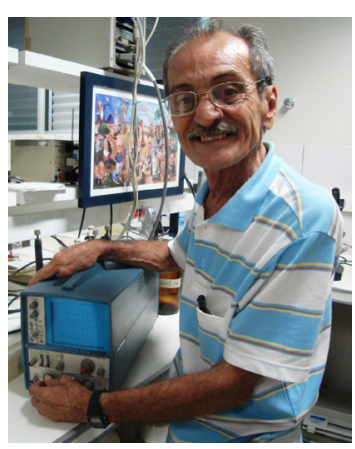

Crédito: Prof. Pedro Magalhães.

Após retornar em 1976 ao Ceará, vinculou-se via concurso público ao Departamento de Fisiologia e Farmacologia da UFC como Professor Assistente de Biofísica, vago desde a aposentadoria do antigo catedrático Prof. Codes y Sandoval. Em 1978, compôs junto com a Profa. Glauce Viana, o Prof. Hélio Rola, o Prof. Luiz Capelo, o Prof. Marcus Vale e o Prof. Manassés Fonteles, o núcleo fundador do Mestrado em Farmacologia, primeiro na área da saúde em nosso Estado. Além de atuação notável no suporte eletrônico de equipamentos científicos de diversos laboratórios de pesquisa, foi pioneiro na UFC em estudos de eletrofisiologia. Em 2002 completou a formação com a tese de Doutorado "Estudo comparativo de parâmetros elétricos na absorção de substratos $\mathrm{Na}^{+} / \mathrm{H}^{+}$-dependentes em epitélio jejunal e ileal de coelho em câmaras de Üssing”, sob a supervisão do Prof. Manassés Fonteles e a co-orientação do Prof. Aldo Lima.

De espírito agregador, o Prof. Eduardo foi eleito por diversas vezes Chefe do Departamento de Fisiologia e Farmacologia, onde atuou em prol da experimentação animal para elevar o ensino e a pesquisa científica no Porangabussu, outrora restrita aos antigos Institutos Básicos. Instituído na Reforma Universitária de 1968, o DFF logo instalou um biotério, dotado de canil, ranário e grande salão, ventilado naturalmente, para a criação de roedores (ratos, camundongos e cobaias), o qual servia de suporte didático e de investigação biomédica. No intuito de alertar a comunidade acadêmica local para a questão, ergueu em 1982 na entrada de serviço do DFF a estátua de um cão vadio em homenagem aos animais usados na rotina acadêmica. Aliás, tal escultura foi confeccionada com recursos próprios pela genitora dele, D. Angélica Ellery Torres da Silva, artista plástica formada na Academia de Belas Artes do Rio de Janeiro.

Nesta era, todo o processo de criação, manutenção, utilização e até o descarte dos animais de experimentação eram de responsabilidade exclusiva dos docentes, sem qualquer providência da Administração Superior! ${ }^{1}$ Entre nós, o Prof. Eduardo foi pioneiro na peleja em implementar mínimas condições sanitárias ao biotério do DFF, que sequer dispunha de funcionário como responsável técnico, seja veterinário ou biólogo, contando apenas com a boa vontade de servidores terceirizados, sob contratos precários. Ante a desídia de muitos colegas de então, o Prof. Eduardo providenciava a compra de ração e maravalha, transportada inclusive na própria Belina II. Sob a insistência dele, os servidores tiveram pela primeira vez acesso a equipamentos de proteção individual, considerados excêntricos à época.

Foi assim, mediante o esforço de gerações de docentes, pós-graduandos, bolsistas de iniciação científica e servidores que foi aperfeiçoada no DFF a prática acadêmica de criação de animais de laboratório. Por certo, eventual avaliação externa poderá ainda recomendar melhores condições operacionais ao novo Biotério Prof. Eduardo Torres bem como no zelo ético ainda mais estrito na manipulação dos animais de experimentação pelas novas gerações de pesquisadores. E, tivéssemos a ventura de ainda contar com o Prof. Eduardo, julgo estaria ele a demandar da Administração Superior da UFC a completa institucionalização do novo Biotério Setorial do Campus do Porangabussu.

Oxalá esta reflexão sirva para atentar ser o processo social um rio, ora encachoeirado, às vezes a voltear a ponto de nos dar impressão de retrocesso, tal qual estamos atônitos a viver esta era de distopia. Mas, de fato, o rio sempre busca o desnível e após tantas voltas, flui sempre na direção da foz.

${ }^{1}$ Só em 2008 veio a ser promulgada a Lei Arouca (No 11.794), regulamentando o uso de animais em pesquisa e ensino no país, ao criar o Conselho Nacional de Controle de Experimentação Animal (Concea) e nas Instituições a Comissão de Ética no Uso de Animais (Ceua).

Armenio Aguiar dos Santos ${ }^{1}$.

1 Universidade Federal do Ceará (UFC), Fortaleza, Ceará, Brasil.

Como citar:

Santos AA. Elegia ao Professor Eduardo Torres. Rev Med UFC. 2019 out-dez;59(4):6. 